\title{
UMA FLOR BROTARÁ DO SOL DE NOSSAS LEMBRANÇAS: POR UM A(NAR)TIVISMO INDÍGENA NO BRASIL
}

\author{
Osmar Moreira dos Santos ${ }^{1}$
}

\begin{abstract}
Resumo: Trata-se de uma reflexão sobre o retorno, em diferença, da noção de sociedade contra o Estado articulada a partir de uma tecnologia dos signos tanto para um devir revolucionário nas pessoas quanto para um esvaziamento do poder no âmbito do Estado como instituição de direito público.
\end{abstract}

Palavras-Chave: corpos marcados; ativação de memórias; reversão de discursos; prática política indígena.

\section{WILL COME A FLOWER REMINDERS OF OUR SUN: \\ BY AN A(NAR)CTIVISM INDIGENOUS IN BRAZIL}

\begin{abstract}
It is a reflection on the return, in difference, the notion of society against the state articulated from a technology of signs for both a revolutionary becoming the people as to a power drain in the State as public law .
\end{abstract}

Keywords: marked bodies; activation memories; reversal of speeches; practice indigenous policy.

\section{INTRODUÇÃOO}

Quando ainda criança, em zona rural do município de Itapetinga - BA, ouvia minha mãe, tios, entre outros, dizerem que a mãe da minha avó, havia sido "pegada no mato" como um bicho. Era uma índia. E provavelmente não seja exagero dizer que, sobretudo em regiões mais distantes de centros urbanos, por todo o Brasil, crianças dos anos sessenta e setenta, do século XX, tenha ouvido frases semelhantes a que ouvi sobre nossos antepassados.

Mesmo habitando a zona rural e vivendo e compartilhando a vida num pequeno mundo distante da "civilização", havia, clara, uma linha divisória entre nós e eles (nossos antepassados). E não há dúvida de que essa linha foi colocada com a ocupação europeia da América ou

1 Professor Titular atuando em Literatura e Metodologia da Pesquisa em Crítica Cultural na Universidade do Estado da Bahia, Campus II/Alagoinhas. Tem como área de interesse: tropicalismo, cinema novo, subalternidade, micropolítica e políticas da subjetividade. Endereço eletrônico: osmar.moreira@uol.com.br. 
Novo Mundo. Aquela "gente", os gentios, a ser salva, devia ser encarada, pelos invasores, não apenas como bárbaros que precisariam de novos "pastores do ser", mas para justificar essa condição de pré-humanidade dos índios, ainda os interpretavam como animais selvagens como qualquer outro: uma onça, uma cobra, um jabuti.

E o papel decisivo nessa demarcação parece ter sido o trabalho colonial tendo por dispositivo a língua, tanto a portuguesa, como as indígenas. Façamos este exercício filosófico: se a língua de qualquer povo, independentemente de seu estágio civilizatório, é a condição, na infância, para que o humano se exercite, se defina e se afirme como tal, o que teria acontecido se alguma espécie de barbárie tivesse inviabilizado esse exercício? Não seria a memorização e repetição de valores ocidentais e cristãos, através do teatro e da catequese, na própria língua do índio, uma forma de despejá-los de sua língua ou de suas línguas, na medida em que separava a palavra (indígena) das coisas (indígenas) para impor outras coisas (a do ocidental cristão)? E se a coisa, em pauta, na pedagogia da memorização e da repetição (em língua indígena), fosse o próprio sentido do ser (humano) destituído de seu universo de referência ou tendo que assumir um outro universo absolutamente estranho e soturno?

Assim, crianças indígenas, no interior das tribos, e sob o impacto dessa pedagogia da memorização imposta pelo colonizador, não só teriam perdido a sua potência de brincar com a nomeação e renomeação do mundo à sua volta, conforme seus valores, suas experiências e práticas estético-políticas e existenciais, mas teriam sido forçados, duplamente, a exercitarem a sua língua ao mesmo tempo como um dispositivo que os igualavam aos animais (e não como um exercício do humano) e como um aparelho de captura que os destituíam de sua historicidade, condenando-as a repetir a história do colonizador. Isso no melhor das hipóteses, pois o pior já sabemos: dizimação e genocídio.

Essa prática teológica de uso das línguas ocidentais ou não ocidentais por parte dos colonizadores europeus, acoplada a uma geometrização do mundo conforme a lógica ocidental emergente no século XVI, vai estabelecer, daí em diante, os parâmetros para as várias formas de divisão e cercados. De um lado, e de um ponto de vista histórico, os bárbaros; de outro, os civilizados, os portadores da "boa nova"; de outro, e de um ponto de vista filosófico (século XVIII), os irracionais ou destituídos da faculdade de pensar; do outro, os racionais e detentores das formas do conhecimento e da verdade; de outro lado, e de um ponto de vista estético (século XIX), os que já nascem dentro de uma língua ou sistema de representação, sem atribu- 
tos para distanciarem-se deles e se afirmarem como sujeito da história, permanecendo como pedras e animais; de outro, os demiurgos, os senhores da palavra e dos processos de criação.

E se aquela frase referida à índia "pegada no mato", tão naturalizada, ou aparentemente sem importância, se tornasse um dispositivo para se questionar esses cercados, por onde, numa lógica infantil, começaríamos uma desmontagem? Talvez começando pelo deslocamento de um dos elementos de designação: "mato". Que é o mato? Se se refere à floresta e se o índio, como um ser humano, é o senhor que coloniza a floresta, por que "mato", com sentido de floresta, seria um atributo negativo? Ou ainda, se o índio (nesse caso a índia) é o senhor da floresta por que seria uma presa fácil do homem branco civilizado? Será que o homem branco, ou europeu, além da dizimação ao longo de quatro séculos, agora, em final do século XIX, já teria instalado um sistema de vigilância e captura no interior das florestas brasileiras? Por que ainda falta ou, ao menos, por que faltou às crianças dos anos sessenta do século $\mathrm{XX}$, um centro de documentação nas roças e fazendas brasileiras tratando da destruição dos povos e culturas indígenas? Imaginem a curiosidade das crianças ao olharem os mapas da caça ao índio, o conjunto das estratégias do colonizador, seus aparelhos de captura, tortura, destruição e esconderijo dos corpos?

Uma tal pedagogia cultural e libertária, própria de um Estado-nação que respeitasse o seu povo, não iria omitir ou falsificar a noção de "mistura das três raças" como condição de democracia e exemplo para o futuro, simplesmente por que se houve mistura (e com certeza houve) qual o lugar de cada raça - o índio, o negro, o branco — nela, em termos de produção discursiva, instalação de instituições, apropriação dos modos de produção de riquezas e estabelecimento das condições de subjetivação?

\section{MODOS DE SUBJETIVAR, MODOS DE SE LIBERTAR:}

\section{TECNOLOGIAS DO SIGNO E DEVIR REVOLUCIONÁRIO NAS PESSOAS}

Não é a palavra mágica que sustenta ao ser humano a sua dimensão plástica e cósmica, mas a capacidade de indivíduos, tribos, comunidades de esvaziá-la de sua fortuna metafísica e transcendental $^{2}$ e submetê-la a uma permanente oficina, em que cada contexto de luta implica

2 Confrontar os livros Posições, de Jacques Derrida, com Curso de Linguística Geral, de Ferdinand de Saussure. 
agenciamentos diferenciais, práticas discursivas sempre abertas a um devir libertário e socialista.

As oficinas abaixo antes de partilhar dessa vontade de expressão cósmica e transcendental, que recobre a humanidade de misérias e produz os farrapos humanos, convidam a todos/as a reinventarem a sua condição de existência a partir de um radical materialismo cultural ${ }^{3}$, para quem a maior obra de arte seria a vida pós-abolição da luta de classes e com essa distribuição equitativa das riquezas produzidas pela natureza e acumulada pelo conjunto da força de trabalho.

\section{Oficina 1:}

Todo sujeito acontece na linguagem e com a linguagem. Acontecer na linguagem, enquanto sujeito, é se dar conta de que consumimos signos enquanto comemos (produtos da culinária afrodescendente a exemplo da série acarajé, abará, pimenta, poderiam dialética e virtualmente se opor à série MacDonald's numa escala e multiplicidade planetária), enquanto ouvimos (música tonal para contemplar as alturas não é a mesma coisa da atonal para tocar a terra e sentir seu próprio peso), olhamos (o fetichismo burguês formata a realidade de um jeito, a possibilidade libertária, fundada no valor de uso e na socialização da riqueza, implica objetividades novas e outros mundos inaugurais) cheiramos (em vez de crack e cocaína, frutas caindo do pé e nas lembranças luminosas) e tocamos às coisas. Os signos que consumimos podem nos consumir ou serem reelaborados e constituírem a performance de cada um enquanto criadores e/ou reprodutores de realidades.

A palavra não nasce grudada na coisa que representa, uma coisa representada pode, além da palavra, ser recoberta de outros signos, embora haja sempre uma comunidade semântica que encena um imperativo da fala e impõe uma transcendência do significado, uma multiplicidade de agências (a escola, a igreja, o estado, o partido, o dicionário, etc.,) que elege e dissemina sujeitos de enunciação (pastores, políticos, professores, dicionaristas, etc.,) e uma lógica que impõe um modo de pensar e que pode cercear sujeitos consumidores de signos, além de bloquear lhes sua potência de pensar e de perguntar.

\footnotetext{
3 Para uma introdução ao materialismo cultural, ver Para ler Raymond Williams de Maria Elisa Cevasco.
} 
Perguntar sobre quem é que é isso ou aquilo, sob que condições históricas e políticas recebeu tal e qual significado, sob que artimanhas circula numa dada comunidade linguística, qual o ponto de sua implosão ${ }^{4}$ aberto a sujeitos criadores de realidades, é garantir e sustentar um consumo ativo dos signos, e/ou representações, que não paramos de consumir.

Uma miríade de comunas socialistas e libertárias, do ponto de vista de um materialismo cultural, pressupõe a existência de uma inteligência estético-política entre associações de homens, mulheres e crianças livres, capazes ao mesmo tempo de esvaziar o sentido de um poder político absoluto e ao mesmo tempo o sentido absoluto de qualquer signo.

\section{Oficina 2:}

Tomemos a parada Disney como uma feira de signos em movimento e imaginemos além das crianças enfeitiçadas pelo espetáculo, uma invasão de outras crianças que implodissem simbolicamente seus carros alegóricos. Mamulengos e bonecos de pano ridicularizando o sorriso do capital embaixo das perninhas levantadas da pequena princesa ou a serialização de pequenos monstrengos diante do espelho da branca de neve. Ou ainda: o derramamento de baldes de tinta vermelha ou sacos de q suco de groselha simulando as ondas do mar sobre o qual trafegaria o barco do Peter Pan e suas aventuras capitalistas pelo mundo.

Já que uma meta Parada Disney (crianças produzindo oficinas desconstrutivas durante o cortejo) ou uma metanovela das oito (cenas desmontando truques melodramáticos) não costumam fazer parte dos livros didáticos que são impostos às escolas de formação básica brasileiras, por que não inventarmos outra pedagogia do lúdico (nós críticos culturais, artistas, professores, produtores, agitadores e consumidores de cultura massiva e hegemônica) começando por uma arqueologia dos videogames? Imaginem uma festa na escola em que estudantes, em oficinas preparatórias, construíssem a indumentária de seus personagens prediletos e os encenassem numa guerra de símbolos.

4 Ver Gilles Deleuze, Lógica do sentido. 


\section{Oficina 3:}

A constituição de um coletivo não pode prescindir de um devir coletivo de cada indivíduo nem de um devir indivíduo desse mesmo coletivo. O devir coletivo de cada indivíduo significa deixar-se marcar, consumir representações como formas de valor e de perspectivas inaugurais e práticas continuadas. O devir indivíduo do coletivo significa a constituição de um corpo, uma corporação, com vontades alinhadas por princípios e traduzidas por uma sintaxe. O problemático na constituição desses devires é: destruir o indivíduo em nome do coletivo e destruir o coletivo como imposição de um indivíduo.

Há duas noções de coletivo e de indivíduo que precisam aqui ser esconjuradas para que a ciência como ação direta, e disponível a qualquer grupelho, possa ser de novo reencenada e praticada. A primeira noção de indivíduo destruída pelo coletivo deriva da prática nazifascista na política e disseminada por segmentos artísticos e culturais (a Parada Disney, por exemplo). Sua lógica de destruição implica em agir em nome de deus, da família, da pátria e da propriedade, ou ainda, em nome da raça pura, para, em primeiro lugar, impedir o indivíduo do acesso a uma tecnologia do signo (quem inventou deus?, como sobreviver sem o gregarismo da família, como fazer da língua uma pátria dos despejados cultural, territorial e ontologicamente?, quem estabeleceu o cercado, criou as leis que o legitimaram e o projetaram para além dos tempos, constituindo assim uma metafísica da propriedade privada?) em segundo, impedi-lo do acesso à mobilização de um coletivo que multiplique as formas de deus, da família como princípio de uma estética da existência. Mátrias no lugar de pátrias. O sentido sem a priori e como acontecimento em movimento.

A segunda noção de indivíduo destruída pelo coletivo deriva da prática stalinista na política e disseminada por segmentos artísticos culturais. Sua lógica de destruição implica em agir em nome do partido, comunista, evocando seus fundadores, mas traindo e falsificando seus princípios. Um exemplo histórico: a destruição física de dezenas de milhares de bolcheviques revolucionários ou, de forma mais branda, a imposição de uma autocrítica como forma de humilhação pública e de destruição de suas forças de subjetivação. Condição na qual qualquer revolucionário, destituído de sua potência de devir coletivo, ou se suicidaria ou se tornaria um farrapo humano ante o grande czar. 
A prática stalinista disseminada por segmentos artísticos culturais já não se configura mais em impor o chamado realismo socialista aos $\operatorname{artistas}^{5}$ e suas obras, proibindo-lhes a experimentação e impondo-lhes a propaganda partidária como valor estético e universal da classe trabalhadora (artistas e suas obras tiveram energia semiótica suficiente para não sucumbirem a tal barbárie), mas em separar a cultura da política como se formas de fazer e praticar política (mesmo no estado e entre partidos e sindicatos) não fosse cultura, não dependesse de homens, mulheres, que nomeiam situações, produzem representações, fundam lógicas de governar e controlar, e estão, por sua condição histórica, completamente vulneráveis àqueles que detêm a tecnologia dos signos.

\section{Oficina 4:}

Tomando por ponto de partida a atividade coletiva e crítica desenvolvida na disciplina Metodologia da Pesquisa em Crítica Cultural e no Curso de Formação de gestores, produtores, artistas e agitadores culturais, ambas desenvolvidas no Mestrado em Crítica Cultural do DEDC II/UNEB, a primeira como disciplina obrigatória, o segundo, como um curso de extensão, fizemos da arte de pesquisar uma técnica de arrombamento e ocupação de espaços epistemológicos:

\section{Princípio no 1:}

Se a riqueza material existente na face da terra deriva da natureza (água, ar, minérios, luz, etc.,) e da força de trabalho de bilhões de trabalhadores, então é preciso destruir urgentemente a lógica capitalista que: a) valoriza apenas o produto do trabalho e coloca toda a riqueza na mão de poucos parasitas; b) faz do fetiche e do simulacro a realidade nossa de cada dia, impedindo abstrações e objetivações de outras formas de realidade fundadas na est-ética do trabalho e da vida socialista; c) coloca no poder representantes da classe média para destruírem as formas de organização dos trabalhadores e/ou encenarem uma organização mecanicista e burocrática do socialismo condenada ao idealismo e à pura abstração.

5 Para uma reversão dessa noção de realismo socialista, ler Fredric Jameson, $O$ inconsciente político, e Leon Trotski, Literatura e revolução. 


\section{Princípio no 2:}

A crítica cultural só faz sentido se investe contra essa lógica capitalista, implode permanentemente essa noção de cultura que se quer hegemônica, e emerge em cada trabalhador, em cada sujeito anônimo, em cada tribo, em cada coletivo, em cada comunidade, em cada nação, como caixa de ferramentas que permita a cada um, ou em coletividade, a redefinição de uma cultura alternativa e como máquina de guerra.

\section{Princípio no 3:}

Cultura como máquina de guerra implica uma experiência estética e vitalista: se forças da barbárie tentam separar a vida daquilo que a vida pode, as forças plásticas e afirmativas, por outro lado, permitem à vida resistir, criar no limite do que pode, inclusive para transformar essas forças da barbárie em forças afirmativas.

\section{Princípio no 4:}

Toda crítica cultural deve também partir de uma cultura da linguagem: quem nomeou isso e/ou aquilo e sob que condições? Como esvaziar os significados transcendentais e conferir sentido ao mundo de acordo com a nossa potência de renomeá-lo, poetizá-lo? O peso do mundo não deve ficar nem com os camelos, pois esse peso é só uma palavra e seus fantasmas.

\section{Princípio no 5:}

Se o ato de conhecer envolve obstáculos que dizem da predisposição do espírito de quem quer conhecer algo e, ao mesmo tempo, das conquistas técnicas, terminológicas, metodológicas, teóricas de um dado campo do conhecimento, então a crítica cultural deve, antes de tudo, estimular seus pesquisadores a reverem suas memórias como um arquivo público, a lerem um arquivo público como uma série de poemas, a produzirem conhecimento sempre experimentalmente e na fronteira de todas as disciplinas. 


\section{Princípio no 6:}

Se nas frestas e tocas de todos os simulacros e falsificações sobre quem de fato e de direito podem usufruir de toda a riqueza material existente, existem um mercado cultural anônimo, uma ética e uma estética socialista surda, mil formas de sintaxes entre os excluídos, formas indiciárias de intercâmbio e coexistência de todas as temporalidades, e, pipocando em todos os lugares, formas de guerrilhas como em jogos de videogames, então está na hora de começarmos a socializar essas técnicas de arrombamento da lógica cultural do capitalismo tardio, com a afirmação de uma política pública cultural heterotópica.

Ou seja: como na comuna de Paris, desarmar os soldados do prefeito, do governador e do presidente, e armar o povo com muitos livros, bibliotecas comunitárias, cinemas digitais, ilhas de produção caseiras e/ou de fundo de quintal; garantir a eleição, através de amplo debate público, de outros representantes, bem como destituí-los do poder, tão logo pisem na bola e/ou traiam o seu mandato. Os salários, remunerações, dos novos agentes culturais, devem tomar como parâmetro a cultura do dinheiro em movimento na economia solidária e nas cooperativas de consumo e de produção, e termos como único parâmetro de justiça: a apropriação da matéria prima, das máquinas e das fábricas, e distribuí-las a quem de fato produz a riqueza!

\section{MINORIAS A(NAR)TIVISTAS E O CREPÚSCULO DO ESTADO}

Mesmo sem mobilizar, aqui, uma teoria do Estado descrevendo sua natureza e função como pessoa jurídica de direito público, e daí fazer derivar uma imagem de seu crepúsculo, acreditamos que o conjunto de informações e argumentos aqui arrolados e sob o crivo da crítica cultural, poderá apontar uma série de roteiros relevantes para o ativismo indígena.

Comecemos, então, com o Art. $6^{\circ}$ da Constituição Brasileira, de 1988, "São direitos sociais a educação, a saúde, o trabalho, o lazer, a segurança, a previdência social, a proteção à maternidade e à infância, a assistência aos desamparados, na forma desta Constituição" confrontado com Art. $5^{\circ}$ "Todos são iguais perante a lei, sem distinção de qualquer natureza, garantindo-se aos brasileiros e aos estrangeiros residentes no País a inviolabilidade do direito à vida, à liberdade, à igualdade, à segurança e à propriedade, e alguns de seus incisos, o XXII "é garantido o direito de propriedade", o XXIII "a propriedade atenderá a sua função social" e o XXX "é garantido o direito de herança". 
Considerando que tal constituição foi discutida e promulgada quase 500 anos depois daquelas ordens de despejo linguístico, cultural, territorial e ontológica dos povos indígenas, 100 anos depois de mais de 300 anos de escravidão do povo negro — para ficarmos em dois exemplos — qual seria, então, o sentido de "direito à propriedade", "direito de herança", enquanto "iguais perante a lei”, e como condições aos direitos sociais como educação, saúde, trabalho, lazer, segurança, entre outros?

Se compusermos o arquivo contendo documentos e testemunhos relativos àquelas ordens de despejo dos povos indígenas, bem como os relativos aos 300 anos de escravidão do povo negro, nossa constituição cidadã não deveria tratar apenas de direitos — que a rigor, se torna uma retórica vazia - mas de reparação, i. e. reconhecimento do genocídio, devolução das terras aos índios que restaram, política cultural específica, além do pagamento em espécie de trilhões de reais aos remanescentes de índios e de escravos.

Se o Estado assim procedesse - e qualquer senso comum identifica, aqui, um especial sentido de justiça - teríamos uma primeira imagem do Estado funcionando como um instrumento de mediação entre capital e trabalho. E mais que isto: mediaria o empoderamento, legítimo, daqueles que foram excluídos, para, então, fazer sentido as noções de propriedade e de herança.

Senão, qual a seria a propriedade de despejados de sua língua, cultura, território, e de seu próprio ser? Qual seria, ainda, a herança a seus filhos e descendentes? Eis, aqui, de forma surpreendente, a primeira imagem crepuscular do Estado.

O Estado, depois de séculos ou mesmo milênios sendo combatido por parte das sociedades contra o Estado, não teria emergido, com a modernidade histórica e filosófica, como uma instituição forte, emancipadora, a favor e sob o controle da sociedade civil organizada?

Mas até a emergência da Comuna de Paris, na França, em 1871, e dos escritos teóricos de Marx e Engels, compreende-se porque o poder deve ser um espaço vazio e sob controle de communards que, ao mesmo tempo legislam e executam, transformam o exército de guardião do poder para lutar ao lado do povo, em armas, destituem dos altos salários todo o servidor público, socializam riquezas e serviços públicos (LENIN, 2005), ou mais que isto, conforme Marx: se o Estado é sempre controlado pela classe que está no poder (no caso a burguesia) então seria necessário colocá-lo na mão dos trabalhadores que, abolindo as propriedades pri- 
vadas, transformando os burgueses em trabalhadores, e distribuindo, equitativamente, as riquezas, não só a luta de classe estaria abolida, mas a vida humana, tornar-se-ia, enfim, uma obra de arte (TROTSKI, op. , cit.).

A Comuna de Paris, sob liderança anarquista, atingiu, ao longo de 71 dias, essa obra de arte, não pela dizimação de artistas e trabalhadores, por parte da contrarrevolução burguesa, mas pela forma de luta e conquistas libertárias para a humanidade; já os Estados socialistas, liderados pelo stalinismo (entre 1924/1954/1989), além de acabar com o espaço público do debate, dizimar os dissidentes, controlar e submeter a obra de arte, como propaganda de regimes burocráticos e autoritários, acabou com o sonho e a utopia socialista. Eis, aqui, uma segunda imagem do crepúsculo do Estado.

A terceira imagem crepuscular do Estado reúne os elementos que destruíram a Comuna de Paris e Canudos, em nome da República; os elementos que instituíram o nazifascismo e o estado de exceção na forma de democracia, além, claro, de ter derrotado, esmagadoramente, o stalinismo, ao menos como forma de Estado.

Ou seja, o crepúsculo do Estado se dar a ver não pelo enfraquecimento da lei, como um imperativo e execução despótica, mas pela inviabilidade ou esvaziamento do direito.

Se o Estado é uma invenção cultural, que sob o comando da sociedade civil, dos trabalhadores, teria a função de abolir a luta de classe e, inclusive, de destruir-se a si mesmo, como prova de sua potência, o que estamos vivendo, nas chamadas democracias contemporâneas, é o seu estertor.

O que aconteceria ao "estado democrático contemporâneo" se os índios, os negros, as mulheres, os homossexuais, as crianças, os professores, os trabalhadores subalternos, a exemplo dos communards, utilizassem o seu direito constitucional de se reunir, de divulgar suas deliberações, de se colocarem em movimento, onde quer houvesse uma prescrição e imposição de uma lei?

A escola suportaria o estudo, crítica e prática política relativos aos seus regimentos e estatutos por parte dos estudantes, professores e técnico-administrativos?

Considerando a malha jurisdicional, em todos os setores da vida social, a imagem de um Estado forte seria aquela em que déspotas, com máscaras de soberanos, seriam indiferentes às pessoas no espaço público e imporiam e executariam a lei ou, radicalmente ao contrário, a- 
quela em que representantes da miríade de grupos submetessem a lei, como um conjunto de signos vazios e esvaziáveis, à apreciação pública, cujos membros, em assembleias, tivessem o direito inalienável, e sem burocracia, de suprimir essa mesma lei?

Diante dessa imagem do Estado, o que seria, então, a noção de minorias a(nar)tivistas? Minorias ativistas, sem engajarem sua subjetividade como cultura política que desloquem o Estado, não há dúvida, contentam-se com migalhas e doações, como sinônimo de bondade pública, e sem colocarem em questão nem a lei, nem a instituição, com seus doadores, pois, provavelmente seus corpos, sua língua, tenham sido esvaziados de sua força ou simplesmente agem sem refletir. Famintos que estão, apenas adoram e deliram, além de serem indiferentes e confundirem política com religião e vice-versa.

Minorias a(nar)tivistas são de outra natureza. Por que diferentes etnias indígenas no Brasil, além da demarcação de suas terras, do livre direito de preservação de sua cultura, ainda querem aprender a se expressar em língua indígena, como língua primeira?

Se tomarmos, dos arquivos coloniais, também acessados pelos índios atuais, esses versos do Auto representado na festa de São Lourenço, do padre José de Anchieta, em que o índio pintado de diabo diz "Quem bom costume é bailar! Adornar-se, andar pintado, tingir pernas, empenado fumar e curandeirar, andar de negro pintado" (p. 12), vemos que o sentido de se aprender língua tupi, atualmente, não só seria um modo de avaliar a gramática da língua construída pelo colonizador, e difundida como best-seller, entre colonizadores, mas de rever a relação entre os nomes e as coisas (repetições em tupi dos valores religiosos e cosmológicos medievais), reposicionar as manifestações e vontades do tradutor, além de devassar a lógica subjacente de suas proposições ou discurso.

O que aconteceria se estudantes e professores indígenas compusessem outro material, também bilíngue, a partir desses documentos e, além de questionar e esvaziar as prescrições para a Língua Portuguesa, contidas nos Parâmetros Curriculares Nacionais, criassem, conforme direito previsto na Constituição Brasileira, Cap. I, inciso XVIII, associações e cooperativas "a criação de associações e, na forma da lei, a de cooperativas independem de autorização, sendo vedada a interferência estatal em seu funcionamento", com função de institucionalizar, gerir, produzir material que faça circular outras formas de reinvenção de si e de suas comunidades? 
A experiência de ocupação de espaços institucionais, através de secretarias de governo, combinada com a de produção de material artístico e cultural com caráter de reversão do discurso colonial, através de associações e cooperativas, não só seria um dispositivo para se ativar as sociedades contra o Estado, mas um laboratório para a emergência de sociedades sem Estado.

Tal atividade a(nar)tivista, por parte, por exemplo, de minorias indígenas - mas poderia ser por parte de quaisquer outras minorias, e em rede - seria, ao mesmo tempo, uma forma de visibilizar a potência do Estado, em processo de perecimento, a favor de uma poética da existência, bem como, ao contrário, seu completo crepúsculo e decadência, arrastando consigo o homem ocidental e sua noção de humanidade.

potyra kwarasy suí osem agwã

uma flor sairá do sol

gwapenum

ondas do mar

gwapenum

ondas do mar

gwapenum

ondas do mar

xe îasy asepiak

eu vejo a lua

nde îasy i

mas não há lua

xe îasytata'y i omãê pe eu olho para as estrelas

nde xe îasytata'y i

mas não há estrelas

xe mamoã asepiak

eu vejo apenas vagalumes

nde mamoã resepiak

você vê apenas vagalumes

a'e mamoã osepiak

ele, ela vê apenas vagalumes 


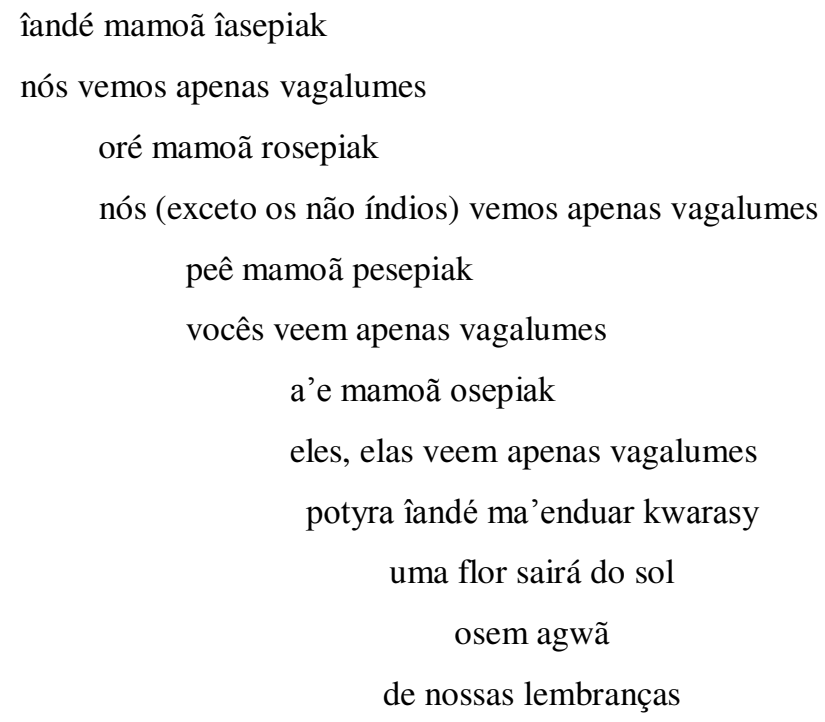

Fazer emergir o menor, o minoritário, numa literatura maior (DELEUZE; GUATARRI, 1997), canônica, é dobrar a língua como, ainda, a única coisa que resta como condição para se testemunhar a favor daqueles povos que, ao longo dos últimos 500 anos, foram destituídos de sua língua, cultura, território e de seu próprio ser.

O poema acima, intitulado Potyra kwarasy suí osem agwã, escrito em língua tupi, acompanhado de sua tradução em português, pelo autor deste trabalho, e como um dos resultados da oficina de língua tupi, ministrada pela Profa. Consuelo de Paiva Godinho Costa da Universidade do Sudoeste da Bahia (UESB), em maio de 2014, é não apenas a abertura de uma série de atividades de um projeto de pesquisa filiado ao Programa de Pós-Graduação em Crítica Cultural, do Campus II da UNEB/Alagoinhas, tais como o estudo permanente e regular de língua, literatura e cultura indígena, oferecimento de disciplina, com tal conteúdo, no curso de Letras com Habilitação em Língua Portuguesa e Literaturas e o estabelecimento de convênio com uma escola municipal de Alagoinhas, como um projeto piloto de implantação de língua tupi na educação fundamental e média, mas, também, a abertura de uma série para 
se pensar o sentido de duplicidade da literatura e seu a(nar)tivismo como condição de contemporaneidade.

Para as centenas de comunidades indígenas, hoje, no Brasil e na América Latina, lutando por seus direitos linguísticos e culturais e, principalmente, pela reapropriação de suas terras, não basta uma literatura brasileira, ou em qualquer língua nacional, com temática indígena, para assegurar-lhes as ferramentas de combate às formas de controle do estado e suas vinculações ao capital, mas, apenas através de um linguajamento e/ou bilinguismo radical reapropriar-se, também, de outras formas de se enunciar, de se posicionar, em relação aos arquivos do ocidente.

Duplicar uma literatura, portanto, é constituir como antídoto à identidade de um texto, um "nem isso", "nem aquilo", nem literatura brasileira, nem literatura tupi, mas oferecer, na fatura do texto, as linhas gerais e segmentadas de um mapa (DELEUZE; GUATARRI, 1995) que indique a experimentação simbólica, a partir de uma ordem discursiva; a construção de um inconsciente político, dramatizando as marcas de um corpo de um sujeito ou de uma cultura; a abertura de conexões entre campos disciplinares distintos e capazes de compor uma máquina de guerra antifascista; o desbloqueio do corpo sem órgãos, como condição de dessubjetivação libertária; a constituição de formas de representação desmontáveis e remontáveis; o estabelecimento de condições para uma produção teatral e performática; o lugar do desejo e da política como ponto de ruptura assignificante.

Assim, se na literatura indianista, e seu cânone, ainda se vê nas ondas do mar, os signos de uma espera, numa literatura dupla e bilíngue se recolhe as conchas deixadas pelas ondas como ferramentas de construção e reinvenção do futuro. A lua e as estrelas cedem lugar aos vagalumes e os coletivos de leitores, professores e escritores indígenas, bem como os de não índios comprometidos com essas questões, engajam suas memórias como prática de um devir humano da humanidade.

\section{REFERÊNCIAS}

AGAMBEN, Giorgio. O que resta de Auschwitz: o arquivo e a testemunha - Homo Sacer III. Trad. Selvino J. Assmann. São Paulo: Boitempo, 2003.

AGAMBEN, Giorgio. Infancia e historia: destrucción de la experiência y origen de la historia. Trad. Silvio Mattoni. Cordoba, Argentina: Adriana Hidalgo Editora, 2011. 
AGAMBEN, Giorgio. O reino e a glória: homo sacer, II, 2. São Paulo: Boitempo Editorial, 2011b.

AGAMBEN, Giorgio. Estado de exceção. Trad. Iraci D. Poleti. São Paulo: Boitempo Editorial, 2004.

AGAMBEN, Giorgio. O que é contemporâneo? E outros ensaios. Trad. Vinicius Nicastro Honesco. Chapecó: Argos, 2010.

AGAMBEN, Giorgio. Homo sacer: o poder soberano e a vida nua I. Trad. Henrique Burigo. Belo Horizonte: Editora da UFMG, 2010b.

AGAMBEN, Giorgio. O homem sem conteúdo. Trad. Cláudio Oliveira. Belo Horizonte: Autêntica, 2012.

ANDRADE, Oswald de. Pau-Brasil. 5. ed. São Paulo: Globo/SEC-SP, 1991.

ANDRADE, Oswald de. A utopia antropofágica. São Paulo: Globo/SEC-SP, 1990.

BALIBAR, Étienne. A filosofia de Marx. Trad. Lucy Magalhães. Rio de Janeiro: Jorge Zahar Editor, 1995.

BENJAMIN, Walter. Reflexões sobre a criança, o brinquedo e a educação. São Paulo: Duas Cidades; Editora 34, 2002.

BENJAMIN, Walter. Passagens. Trad. [do alemão] Irene Aron; trad [do francês] Cleonice Paes Barreto Mourão. Belo Horizonte: Editora da UFMG; São Paulo: Imprensa Oficial do Estado de São Paulo. 2009.

BENJAMIN, Walter. Magia e técnica, arte e politica: ensaios sobre literatura e história da cultura. Trad. Sérgio Paulo Rouanet. São Paulo: Brasiliense, 1986. (Obras escolhidas, vol. 1).

BORGES, Jorge Luis. Elogio da sombra; Um ensaio autobiográfico. Trad. [para Elogio da sombra] Carlos Nejar e Alfredo Jacques; trad. [para Um ensaio autobiográfico] Maria da Glória Bordini. São Paulo: Globo, 1993.

BURKE, Peter. A Escola dos Annales (1929-1989): a Revolução Francesa da historiografia. Trad. Nilo Odalia. São Paulo: Editora da UNESP, 1997.

CASTRO, Eduardo Viveiros de. Araweté: os deuses canibais. Rio de Janeiro: Jorge Zahar Editor, 1986.

CLASTRES, Pierre. A sociedade contra o Estado. Trad. Theo Santiago. 4. ed. Rio de Janeiro: Francisco Alves, 1988.

DELEUZE, Gilles. Em que se pode reconhecer o estruturalismo? In: A ilha deserta e outros textos - Textos e entrevistas (1953 - 1974). Edição David Lapoujade; Organização Luiz B. L. Orlandi; Trad. Hilton F. Japiassu. São Paulo: Iluminuras, 2006).

DELEUZE. Gilles. Conversações. Trad. Peter Pál Pelbart. Rio de Janeiro: Ed. 34, 1992.

DELEUZE, Gilles. Lógica do sentido. Trad. Luiz Roberto Salinas Fortes. São Paulo: Perspectiva, 1988.

DELEUZE, Gilles, GUATARRI, Félix. Introdução: Rizoma. In: Mil Platôs: capitalismo e esquizofrenia, vol. 1. Trad. Aurélio Guerra Neto e Celia Pinto Costa. Rio de Janeiro: Ed. 34, 1995. 
Pontos de Interrogação, v. 4, n. 2, jul./dez. 2014

Revista do Programa de Pós-Graduação em Crítica Cultural

Universidade do Estado da Bahia (UNEB), Campus II — Alagoinhas — BA

DERRIDA, Jacques. Posições. Trad. Tomaz Tadeu da Silva. Belo Horizonte: Autêntica, 2001.

DEUTSCHER, Isaac. Stalin: uma biografia política. Trad. Luiz Sérgio Henriques. Rio de Janeiro: Civilização Brasileira, 2006.

FOUCAULT, Michel. Nietzsche, Freud e Marx / Theatrum Philosoficum. Trad. Jorge Lima Barreto. Porto: Edições RÊS, s/d. Cadernos de teoria e conhecimento 1.

FOUCAULT, Michael. Metodologia para o conhecimento do mundo: como se desembaraçar do marxismo. In: Ditos e Escritos: repensar a política. Trad. Ana Lúcia Paranhos Pessoas. Volume VI. Rio de Janeiro: Forense Universitária, 2010.

GALLO, Sílvio. O professor-artista: educação de si e revolução molecular. In: SANTOS, Cosme; GARCÍA, Paulo César Souza; SEIDEL, Roberto Henrique (Org.). Crítica cultural e educação básica: diagnósticos, proposições e novos agenciamentos. São Paulo: Cultura Acadêmica, 2011.

GUATTARI, Félix. Restauração da cidade subjetiva. In: Caosmose: um novo paradigma estético. Trad. Ana Lúcia de Oliveira e Lúcia Cláudia Leão. Rio de Janeiro: Ed. 34, 1992.

GUINSBURG, Carlo. Mitos, emblemas, sinais: morfologia e história. São Paulo: Companhia das Letras, 1990.

JAMESON, Fredric. A lógica cultural do capitalismo tardio. In: Pós-modernismo: a lógica cultural do capitalismo tardio. São Paulo: Ática, 1996.

LUKÁCS, Georg. O que é marxismo ortodoxo?, In: História e consciência de classe: estudos sobre dialética marxista. Trad. Rodnei Nascimento. São Paulo: Martins Fontes, 2003.

LENIN, Vladimir Ilitch. $O$ Estado e a revolução. A revolução proletária e o renegado Kautsky. Trad. Henrique Canary. São Paulo: Edit Inst.José Luis e Rosa Sundermann, 2005.

MARQUES, Reinaldo. Memória literária arquivada. In: Aletria - Revista de Estudos de Literatura, Belo Horizonte, FALE/UFMG, n. 18, p. 105-120, jul./dez. 2008.

MARX, Karl. A ideologia alemã. Trad. José Carlos Bruni e Marco Aurélio Nogueira. São Paulo: Editora Hucitec, 1999.

MARX, Karl. O 18 Brumário e Cartas a Kugelmann. Trad. Leandro Konder e Renato Guimarães. Rio de Janeiro: Paz e Terra, 1997.

MÉSZÁROS, István. Para além do capital: rumo a uma teoria da transição. Trad. Paulo César Castanheira e Sérgio Lessa. Campinas: Editora da UNICAMP, São Paulo: Boitempo, 2002.

MIGNOLO, Walter. Linguajamento, 2003. In: CÉSAR, América Lúcia Silva, SOUZA, Arissana Braz Bomfim de, COSTA, Suzana Lima. Para uma cartografia da educação escolar indígena. Pontos de Interrogação. Alagoinhas, v.2, n.2, jul./dez. 2012. Disponível em http://www.poscritica.uneb.br/revistaponti/arquivos/volume2-n2/4.PARA-UMACARTOGRAFIA-DA-EDUCACAO-revistaponti-vol2-n2.pdf . Acesso: em 28 abr. 2014.

SANTIAGO, Silviano. O cosmopolitismo do pobre: crítica literária e crítica cultural. Belo Horizonte: Editora UFMG, 2008. 
SANTIAGO, Silviano. Uma literatura nos trópicos: ensaios sobre dependência cultural. São Paulo: Perspectiva, 1978.

SANTOS, Osmar Moreira dos. Folhas venenosas do discurso: um diálogo entre Oswald de Andrade e João Ubaldo. Salvador: Quarteto, 2002.

SANTOS, Osmar Moreira dos. Um Oswald de bolso: crítica cultural ao alcance de todos. Salvador: Quarteto, 2010.

SANTOS, Osmar Moreira dos. Comuna de Paris como cidade literária. In: OLIVEIRA, André (et alii) org. O que pode um subalterno: sobre história, literatura, crítica cultural e outras máquinas. Salvador: Quarteto, 2012.

SANTOS, Osmar Moreira dos. Núcleo de cultura nas escolas: outro modo de praticar política cultural na Bahia. In: SANTOS, Cosme Batista dos (et alii) org. Crítica cultural e educação básica: diagnósticos, proposições e novos agenciamentos. São Paulo: Cultura Acadêmica, 2011.

SANTOS, Osmar Moreira dos e SILVA, Evanildes Teixeira. Formação cultural do estudante de Letras. In: SANTOS, Cosme Batista dos et al. (Org.). Crítica cultural e educação básica: diagnósticos, proposições e novos agenciamentos. São Paulo: Cultura Acadêmica, 2011b.

SANTOS, Osmar Moreira dos. Crítica cultural: campos de trabalho e trabalho de campo. In: LIMA, Ari e COSTA, Edil (Org.). Estudos de crítica cultural: diálogos e fronteiras. Salvador: Quarteto, 2010.

SARTRE, Jean-Paul. Crítica da razão dialética. Rio de Janeiro: DP\&A, 2002.

SEMINÁRIO ARQUIVOS, TESTEMUNHOS E POBREZA NO BRASIL, IV Procad Pós-Lit (UFMG)/Pós-Crítica (UNEB), set./2013, Praia do Forte - BA. Anotações. VENÂNCIO,

Renato. Sistema de Arquivos Institucionais Gerais da UFMG; FLEXOR, Maria Helena Matue Ochi. Leitura de documentos históricos; MATOS, Maria Teresa. Arquivo Público da Bahia.

TROTSKI, Leon. Literatura e revolução. Trad. Luiz Alberto Moniz Bandeira. Rio de Janeiro: Jorge Zahar Editor, 2007.

XIAOBO, Liu. June Fourth Elegies. Trad. [do chinês] Jeffrey Yang. Minneapolis, Minnesota: Graywolf Press, 2012.

ZERZAN, John. Twilight of the Machines, Feral House, 2008

Recebido em: 19 de outubro de 2014.

Aceito em: 20 de novembro de 2014. 